Bull. Egypt. Soc. Physiol. Sci. 40 (1), 15-31

\author{
Bull. of Egyp. Soc. Physiol. Sci. \\ (Official Journal of Egyptian Society for Physiological Sciences) \\ (pISSN: 1110-0842; eISSN: 2356-9514)
}

\title{
Effect of the combination between empagliflozin and calcipotriol on cadmium-induced testicular toxicity in rats
}

\author{
Ahmed M. Kabel a,b,", Hany M. Borg c, Remon S. Estfanous d, Maaly A. Abd Elmaaboud a \\ ${ }^{a}$ Department of Pharmacology, Faculty of Medicine, Tanta University, Tanta, Egypt \\ ${ }^{b}$ Department of Clinical Pharmacy, College of Pharmacy, Taif University, Taif, Saudi Arabia \\ ${ }^{c}$ Physiology department, Faculty of Medicine, Kafrelsheikh University, Egypt \\ d Anatomy and Embryology Department, Faculty of Medicine, Tanta University, Tanta, Egypt
}

Received: 17 July 2019

Accepted: 1 Sept 2019

Available online: 1 Jan 2020

\section{Keywords}

- Empagliflozin

- Calcipotriol;

- Cadmium

- Testis

- Rats

\begin{abstract}
The aim of this study was to assess the effect of empagliflozin and/or calcipotriol on cadmium-induced testicular toxicity in rats. Sixty male Wistar rats were divided into 6 equal groups: Control; cadmium; cadmium + empagliflozin; cadmium + calcipotriol; cadmium + Carboxymethyl cellulose and cadmium + empagliflozin + calcipotriol. Testicular enzymes, serum testosterone, luteinizing hormone and follicle stimulating hormone were measured. Also, testicular tissue antioxidant enzymes, interleukin-6 (IL-6), transforming growth factor beta 1 (TGF- $\beta 1$ ) and sperm characteristics were determined. Parts of the testes were subjected to histopathological and immunohistochemical examination. Empagliflozin/calcipotriol combination restored the testicular enzymes, sperm characteristics, hormonal profile and the antioxidant defenses compared to the use of each of these drugs alone. Also, this combination significantly ameliorated the inflammatory processes and induced significant improvement of the histopathological, and immunohistochemical picture compared to the use of each of these drugs alone. So, empagliflozin/calcipotriol combination might represent a promising therapeutic modality for amelioration of cadmium-induced testicular toxicity.
\end{abstract}

Corresponding author: Ahmed M. Kabel, El-Geish street, Faculty of Medicine, Tanta University, Department of Pharmacology, Tanta, Egypt; E-mail: ahmed.kabal@med.tanta.edu.eg; Tel.: +201102344533, +966564833526; Postal code: 31527 


\section{INTRODUCTION}

Cadmium is one of the toxic heavy metals that was used for a long time as a corrosion-resistant plating on steel and as red, orange and yellow pigments to color glass and to stabilize plastic [1]. Cadmium use is generally decreasing due to its toxic effects on various body systems even if it was absorbed at relatively low doses [2]. Although its main repository organ is the kidney, its toxic effects are demonstrated in the testes even before pathological changes occur in other organs [3]. The mechanisms of cadmium-induced testicular toxicity include induction of oxidative stress, increased production of the proinflammatory cytokines and induction of apoptosis in the spermatogenic cells. These effects may lead to damage of the gonadal functions which may significantly affect male fertility [4].

Empagliflozin is one of the antidiabetic drugs that selectively inhibits sodium glucose cotransporter-2 [5]. It has a minimal possibility to produce hypoglycaemia than other antidiabetic drugs due to its insulin-independent mechanism of action [6]. Recent studies reported that empagliflozin may have potent antioxidant, anti-inflammatory and antiapoptotic effects $[7,8]$. Moreover, empagliflozin may regulate different enzymes involved in DNA replication, transcription and protein synthesis which are vitally needed for spermatogenesis [9]. These properties may give a role to empagliflozin in amelioration of cadmium-induced testicular toxicity.

Calcipotriol is one of the synthetic derivatives of calcitriol (Vitamin D) which is widely used for treatment of certain disorders of the skin [10]. Vitamin $\mathrm{D}$ and its derivatives were reported to have potent antioxidant, anti-inflammatory and anti-apoptotic properties that may ameliorate oxidative stress and inflammation in various body tissues [11]. Moreover, calcipotriol was proven to antagonize TGF- $\beta 1$ signaling via vitamin $\quad \mathrm{D}$ receptor/Smad3 genomic crosstalk which blocks Smad residency on chromatin and inhibits acetylation of histone $\mathrm{H}_{3}$ leading to suppression of the pro-inflammatory cytokines at the gene expression level [12]. The aim of this study was to assess the effect of empagliflozin and/or calcipotriol on cadmium-induced testicular toxicity in rats.

\section{Materials and Methods}

\subsection{Chemicals and drugs}

Cadmium sulfate salt was purchased from Guangzhou Fischer Chemical Co., Ltd, Guangdong, China. Empagliflozin was purchased from Boehringer Ingelheim, Germany. Calcipotriol was obtained from Hölzel Diagnostika (Hohenzollernring, Germany). Carboxymethyl cellulose (CMC) was purchased from ADWIC Co., Cairo, Egypt. All other chemicals were purchased 
from Sigma Aldrich Co., Saint Louis, Missouri, USA. All reagents and chemicals used were of analytical grade. Cadmium sulfate was dissolved in distilled water. Empagliflozin and calcipotriol were suspended in $0.5 \% \mathrm{CMC}$ solution.

\subsection{Experimental animals}

This study was carried out on 60 male adult sexually mature fully grown Wistar rats weighing about 120-200 grams. They were allowed to acclimatize for two weeks before starting the experiment. Rats were kept in a special room at a constant temperature of $25 \pm 3^{\circ} \mathrm{C}$ with relative humidity of $55 \pm 5 \%$ and were exposed to 12 h light/dark cycle. They were fed with standard diet and distilled water provided ad libitum. All the experiments were conducted according to the National Research Council's guidelines. This study was approved by the Research Ethics Committee of faculty of medicine, Tanta University, Egypt. Animal handling was followed according to Helsinki declaration of animal ethics.

\subsection{Experimental design}

Animals were randomly divided into six equal groups of 10 rats each as follows: Group 1: Control group; received daily intraperitoneal injection of distilled water at $0.2 \mathrm{~mL} / 100 \mathrm{~g}$ for 3 consecutive days.

Group 2: Received intraperitoneal injection of cadmium sulfate in a dose of $0.3 \mathrm{mg} / \mathrm{kg}$ body weight for 3 days [13].
Group 3: Cadmium sulfate + Empagliflozin group; received empagliflozin in a dose of $10 \mathrm{mg} / \mathrm{kg} /$ day by oral gavage for six weeks before starting cadmium injection and continued for 3 days concurrently with cadmium sulfate [14].

Group 4: Cadmium sulfate + Calcipotriol group; received calcipotriol in a dose of 20 $\mu \mathrm{g} / \mathrm{kg} /$ day by oral gavage for six weeks before starting cadmium injection and continued for 3 days concurrently with cadmium sulfate [15]..

Group 5: Cadmium sulfate + CMC group; received $0.5 \%$ CMC solution daily by oral gavage for six weeks before starting cadmium injection and continued for 3 days concurrently with cadmium sulfate.

Group 6: Cadmium sulfate + Empagliflozin + Calcipotriol group; received empagliflozin concomitantly with calcipotriol in the above mentioned doses for six weeks before starting cadmium injection and continued for 3 days concurrently with cadmium sulfate.

\subsection{Assessment of serum biochemical} parameters

At the end of the study, rats were anaesthetized with thiopental sodium (30 $\mathrm{mg} / \mathrm{kg}$ body weight, intraperitoneal). Blood was collected from the retro-orbital plexus, centrifuged and sera were separated and used for assessment of serum luteinizing hormone (LH) and follicle-stimulating hormone (FSH) using ELISA kits obtained 
from DRG Diagnostics, Marburg, Germany according to the manufacturer's protocol. Also, serum testosterone was assessed using ELISA kits obtained from Microlisa AMGENIX Int, Inc. USA according to the instructions of the manufacturer.

\subsection{Preparation of the testicular tissue} samples

The testis and the epididymis were removed, cleared and weighed. The left testis was rinsed with ice-cold saline, weighed and homogenized. Then, the homogenate was centrifuged at $3000 \mathrm{rpm}$ for $20 \mathrm{~min}$ and the supernatant was used for assessment of the tissue biochemical parameters. The right testis was used for histopathological and immunohistochemical examination

2.6. Assessment of testicular tissue oxidative stress parameters, interleukin 6 (IL-6) and transforming growth factor beta 1 (TGF- $\beta 1)$

Tissue catalase (CAT) was measured according to Sinha [16]. Tissue glutathione reductase (GR) was assessed using kits purchased from Sigma Aldrich Co., USA, according to the instructions of the manufacturer. Tissue thiobarbituric acid derivatives (TBARS) were determined using kits purchased from Cell Biolabs, Inc., San Diego, USA according to the instructions of the manufacturer. Tissue IL- 6 and TGF- $\beta 1$ were measured using ELISA kits supplied by
Sigma Aldrich Co. according to the manufacturer's instructions.

\subsection{Assessment of the activity of the} testicular enzymes

Acid phosphatase (ACP), lactate dehydrogenase (LDH), alkaline phosphatase (ALP), and glucose-6-phosphate dehydrogenase (G6PD) activities were measured using kits supplied by Sigma Aldrich Co. according to the instructions of the manufacturer. Sorbitol dehydrogenase (SDH) was assessed using ELISA kits supplied by Wuhan USCN Business Co., Ltd., according to the manufacturer's protocol. Protein content was determined according to Lowry et al. [17].

2.8. Assessment of the sperm characteristics

Epididymal sperms were collected by slicing the epididymis in $5 \mathrm{~mL}$ of Ham's F10 then incubated for $5 \mathrm{~min}$ at $37^{\circ} \mathrm{C}$ in $5 \%$ $\mathrm{CO}_{2}$ to allow sperms to swim out of the epididymal tubules. Then, one drop of the sperm suspension was put on a glass slide and a cover slip was placed. Ten microscopic fields at 400× magnification were observed using light microscope and the percentage of the motile sperms was evaluated microscopically within 2-4 min of their isolation from the epididymis [18].

Epididymal sperm counts were assessed according to Badkoobeh et al. [19]. $20 \mu \mathrm{l}$ of the sperm suspension was mixed with $20 \mu \mathrm{l}$ of $0.05 \%$ eosin-Y and incubated 
for $2 \mathrm{~min}$ at room temperature for calculation of the percentage of dead sperms. Then, the mixture was placed on a glass slide and examined by bright-field microscope at 400×. Two hundred sperms were counted in each sample and viability percentages were calculated [20].

For assessment of the morphological abnormalities of the sperms, smears were prepared on clean and grease-free slides and allowed to air dry overnight. Then, the slides were stained with $1 \%$ eosin-Y/5\% nigrosin and examined at $400 \times$ for morphological abnormalities such as bicephalic, coiled, amorphous, hook less or abnormal tails [21].

\subsection{Histopathological examination}

The right testes were kept in $10 \%$ formalin solution for $24 \mathrm{~h}$, dehydrated in ethanol and embedded in paraffin blocks. Then, sections were cut at 5 micron thickness, placed on glass slides, stained with hematoxylin and eosin and examined using Leica DM750 Camera Microscope, Leica Microsystems GmbH, Wetzlar, Germany.

2.10. Assessment of nuclear factor kappa-B (NF-кB) (p65) immunostaining

Sections from the right testes were fixed in $10 \%$ neutral buffered formalin. Then, paraffin sections were prepared and stained with rat Anti-NF- $\mathrm{B}$ (p65) antibody purchased from RayBiotech, USA and the slides were examined under light microscope. The activated subunit p65 of
$\mathrm{NF}-\kappa \mathrm{B}$ was determined in the examined tissues and the immunostaining was detected according to the intensity of staining as (+1) weak when nuclear staining was visible at (x200) magnification, (+2) when visible at (x100) magnification and $(+3)$ strong when visible at (x40) magnification [22].

\subsection{Statistical analysis}

The statistical package for the social sciences (SPSS) version 21.0 was used for statistical analysis of the obtained results. Values of the measured parameters were expressed as mean \pm standard error of mean (SEM). For comparison between the different groups, one way analysis of variance (ANOVA) followed by TukeyKramer multiple comparisons test was used. Pearson's correlation coefficient (r) was used to correlate between tissue TBARS and the sperm characteristics. P-values less than 0.05 were considered statistically significant.

\section{Results}

3.1. Effect of different treatments on testicular tissue IL-6 and TGF- $\beta 1$ in the studied groups

Cadmium induced significant increase in tissue IL-6 and TGF- $\beta 1$ compared to the control group. Addition of $\mathrm{CMC}$ induced non-significant effect on these parameters compared to rats treated with cadmium alone. Administration of empagliflozin and/or calcipotriol induced significant decrease in these parameters 
compared to rats treated with cadmium alone. This decrease was significant with empagliflozin/calcipotriol combination compared to the use of each of these drugs alone (Table 1).

3.2. Effect of different treatments on testicular tissue oxidative stress parameters in the studied groups

Administration of cadmium induced significant decrease in tissue CAT and GR associated with significant increase in tissue TBARS compared to the control group. Empagliflozin and/or calcipotriol induced significant increase in tissue CAT and GR associated with significant decrease in tissue TBARS compared to rats treated with cadmium alone. Administration of $\mathrm{CMC}$ induced non-significant effect on the above mentioned parameters compared to rats treated with cadmium alone. Empagliflozin/calcipotriol combination induced significant increase in tissue CAT and GR associated with significant decrease in tissue TBARS compared to the use of each of these drugs alone (Table 1).

3.3. Effect of different treatments on the activity of the testicular enzymes in the studied groups

Administration of cadmium induced significant decrease in tissue ALP, ACP, G6PD, LDH, and SDH compared to the control group. Empagliflozin and/or calcipotriol induced significant increase in these markers compared to rats treated with cadmium alone. Administration of CMC induced non-significant effect on these markers compared to rats treated with cadmium alone. Concomitant administration of empagliflozin and calcipotriol induced significant increase in the above-mentioned markers compared to the use of each of these drugs alone (Table 2).

\subsection{Effect of different treatments on serum} testosterone, LH and FSH in the studied groups

Cadmium induced significant decrease in serum testosterone, FSH and $\mathrm{LH}$ compared to the control group. Addition of $\mathrm{CMC}$ induced non-significant effect on these parameters compared to rats treated with cadmium alone. Administration of empagliflozin and/or calcipotriol induced significant increase in the above-mentioned parameters compared to rats treated with cadmium alone. This increase was significant with empagliflozin/calcipotriol combination compared to the use of each of these drugs alone (Table 3). 
Table 1: Effect of different treatments on the testicular tissue IL-6, TGF- $\beta 1$ and markers of oxidative stress Control Cadmium
Cadmium +

Empagliflozin
Cadmium +

Calcipotriol
Cadmium +

$\mathrm{CMC}$
Cadmium +

Empagliflozin + Calcipotriol

\begin{tabular}{|c|c|c|c|c|c|c|}
\hline $\begin{array}{c}\text { Tissue IL-6 } \\
\text { (pg/ mg } \\
\text { protein) }\end{array}$ & $122.1 \pm 5.5$ & $431.2 \pm 21.3^{*}$ & $310.6 \pm 15.62^{\#}$ & $341.2 \pm 17.2^{\#}$ & $438.7 \pm 22.1$ & $231.5 \pm 13.5^{\text {\#\$}}$ \\
\hline $\begin{array}{c}\text { Tissue TGF- } \\
\beta 1 \\
\text { (pg/mg } \\
\text { protein) }\end{array}$ & $21.15 \pm 1.32$ & $95.2 \pm 5.14^{*}$ & $68.41 \pm 3.52^{\#}$ & $71.82 \pm 3.67^{\#}$ & $92.64 \pm 4.65$ & $45.24 \pm 2.39^{\# \$}$ \\
\hline $\begin{array}{c}\text { Tissue CAT } \\
\text { (U/mg tissue) }\end{array}$ & $28.3 \pm 1.41$ & $13.25 \pm 0.6^{*}$ & $17.35 \pm 0.77^{\#}$ & $18.79 \pm 0.89^{\#}$ & $12.43 \pm 0.54$ & $23.26 \pm 1.13^{\# \$ \bullet}$ \\
\hline $\begin{array}{l}\text { Tissue GR } \\
(\mathrm{U} / \mathrm{g} / \mathrm{min})\end{array}$ & $215.4 \pm 10.2$ & $124.67 \pm 6.5^{*}$ & $145.8 \pm 7.35^{\#}$ & $155.74 \pm 7.6^{\#}$ & $127.35 \pm 6.8$ & $184.83 \pm 8.7^{\# \$ \bullet}$ \\
\hline $\begin{array}{c}\text { Tissue } \\
\text { TBARS } \\
(\mu \mathrm{M} / \mathrm{g} \text { tissue }) \\
\end{array}$ & $8.26 \pm 0.33$ & $62.31 \pm 3.4^{*}$ & $49.5 \pm 2.4^{\#}$ & $43.56 \pm 2.24^{\#}$ & $64.61 \pm 3.7$ & $32.76 \pm 1.7^{\# \bullet \bullet}$ \\
\hline
\end{tabular}

Values were represented as mean \pm SEM

* Significant compared to the control group (p-value less than 0.05); " Significant compared to untreated cadmium group (p-value less than 0.05 );

\$Significant compared to cadmium + empagliflozin group (p-value less than 0.05$) ; \bullet$ Significant compared to cadmium + calcipotriol group (p-value less than 0.05 )

Table 2: Effect of different treatments on the activity of the testicular enzymes

Control Cadmium Cadmium + Cadmium + Calcipotriol

Empagliflozin
Cadmium Cadmium +

$+\mathrm{CMC} \quad$ Empagliflozin + Calcipotriol

\begin{tabular}{|c|c|c|c|c|c|c|}
\hline $\begin{array}{l}\text { Tissue ACP (U/mg } \\
\text { protein) }\end{array}$ & $131.42 \pm 6.25$ & $75.4 \pm 3.4^{*}$ & $101.2 \pm 5.3^{\#}$ & $91.4 \pm 4.92^{\#}$ & $72.5 \pm 3.37$ & $115.4 \pm 5.35^{\# \$}$ \\
\hline $\begin{array}{c}\text { Tissue ALP (U/mg } \\
\text { protein) }\end{array}$ & $144.75 \pm 7.41$ & $88.5 \pm 4.21^{*}$ & $113.2 \pm 5.86^{\#}$ & $102.9 \pm 5.4^{\#}$ & $86.3 \pm 4.1$ & $128.8 \pm 6.42^{\# \bullet}$ \\
\hline $\begin{array}{l}\text { Tissue G6PD (U/mg } \\
\text { protein) }\end{array}$ & $7.17 \pm 0.33$ & $4.21 \pm 0.26^{*}$ & $5.46 \pm 0.25^{\#}$ & $5.21 \pm 0.22^{\#}$ & $4.26 \pm 0.24$ & $6.34 \pm 0.31^{\# \bullet \bullet}$ \\
\hline $\begin{array}{c}\text { Tissue LDH (U/mg } \\
\text { protein) }\end{array}$ & $5.32 \pm 0.23$ & $3.14 \pm 0.11^{*}$ & $3.86 \pm 0.15^{\#}$ & $3.78 \pm 0.16^{\#}$ & $2.99 \pm 0.12$ & $4.67 \pm 0.22^{\# \bullet \bullet}$ \\
\hline $\begin{array}{c}\text { Tissue SDH }(\mathrm{U} / \mathrm{mg} \\
\text { protein) }\end{array}$ & $4.98 \pm 0.26$ & $3.42 \pm 0.13^{*}$ & $3.92 \pm 0.19^{\#}$ & $3.86 \pm 0.18^{\#}$ & $3.35 \pm 0.12$ & $4.57 \pm 0.24^{\# \bullet \bullet}$ \\
\hline
\end{tabular}

Values were represented as mean \pm SEM

* Significant compared to the control group (p-value less than 0.05); \# Significant compared to untreated cadmium group (p-value less than 0.05);

$\$$ Significant compared to cadmium + empagliflozin group (p-value less than 0.05$) ; \bullet$ Significant compared to cadmium + calcipotriol group ( $\mathrm{p}$-value less than 0.05 )

\subsection{Effect of different treatments on the} sperm characteristics in the studied groups

Following administration of cadmium, significant decrease in sperm count and motility with significant increase in the percentage of dead sperms and abnormal sperm forms were observed compared to the control group. Addition of CMC induced non-significant effect on the sperm characteristics compared to rats treated with cadmium alone. Administration 
of empagliflozin and/or calcipotriol induced significant increase in sperm count and motility associated with significant decrease in the percentage of dead sperms and abnormal sperm forms compared to rats treated with cadmium alone. Empagliflozin/calcipotriol combination induced significant improvement in the above-mentioned sperm characteristics compared to the use of each of these drugs alone (Table 4).

\subsection{Correlation between tissue TBARS and} the sperm characteristics

There was significant positive correlation $(\mathrm{P}<0.05)$ between the percentage of dead sperms and abnormal sperm forms, and tissue TBARS while there was significant negative correlation $(\mathrm{P}<$ 0.05 ) between the sperm count and motility, and tissue TBARS (Table 5).

3.7. Histopathological and immunohistochemical results

$$
\text { Administration of cadmium }
$$

induced significant disorganization in the

seminiferous tubules associated with significant decrease in the germinal cells, increased vacuolization and immature germinal epithelial cells in the lumen (Fig. 1b). This was associated with significant increase in NF- $\kappa \mathrm{B}$ (p65) immunostaining (Fig. 2b) compared to the control group. Addition of $\mathrm{CMC}$ induced non-significant effect on the histopathological and immunohistochemical picture compared to the untreated cadmium group (Fig. 1c, 2c). These changes were significantly improved in the groups treated with empagliflozin or calcipotriol (Fig. 1d, e) with significant decrease in NF- $\mathrm{B}$ (p65) immunostaining (Fig. 2d,e) compared to rats treated with cadmium alone. Empagliflozin/calcipotriol combination induced significant improvement in the histopathological and immunohistochemical picture compared to the use of each of these drugs alone (Fig. 1f, 2f).

Table 3: Effect of different treatments on serum testosterone, LH and FSH

\begin{tabular}{|c|c|c|c|c|c|c|}
\hline & Control & Cadmium & $\begin{array}{c}\text { Cadmium }+ \\
\text { Empagliflozin }\end{array}$ & $\begin{array}{l}\text { Cadmium + } \\
\text { Calcipotriol }\end{array}$ & $\begin{array}{c}\text { Cadmium + } \\
\text { CMC }\end{array}$ & $\begin{array}{c}\text { Cadmium }+ \\
\text { Empagliflozin }+ \\
\text { Calcipotriol }\end{array}$ \\
\hline $\begin{array}{c}\text { Serum testosterone } \\
(\mathrm{ng} / \mathrm{dl})\end{array}$ & $226.3 \pm 11.7$ & $\begin{array}{l}75.3 \pm \\
3.74^{*} \\
\end{array}$ & $121.4 \pm 5.77^{\#}$ & $\underset{\#}{102.45 \pm 5.12}$ & $69.93 \pm 3.64$ & $172.4 \pm 9.12^{\# \$ \bullet}$ \\
\hline Serum LH (mIU/ml) & $0.57 \pm 0.04$ & $0.32 \pm 0.02$ & $0.43 \pm 0.03^{\#}$ & $0.40 \pm 0.02^{\#}$ & $34.52 \pm 0.02$ & $0.52 \pm 0.03^{\# \bullet}$ \\
\hline Serum FSH (mIU/ml) & $0.24 \pm 0.02$ & $0.11 \pm 0.01$ & $0.17 \pm 0.01^{\#}$ & $0.16 \pm 0.01^{\#}$ & $0.12 \pm 0.01$ & $0.21 \pm 0.02^{\# \bullet \bullet}$ \\
\hline
\end{tabular}

Values were represented as mean \pm SEM

* Significant compared to the control group (p-value less than 0.05); " Significant compared to untreated cadmium group ( $\mathrm{p}$-value less than 0.05 );

$\$$ Significant compared to cadmium + empagliflozin group (p-value less than 0.05$) ; \bullet$ Significant compared to cadmium + calcipotriol group ( $\mathrm{p}$-value less than 0.05 ) 
Table 4: Effect of different treatments on the epididymal sperm count, motility, \% of dead sperms and $\%$ of abnormal sperms

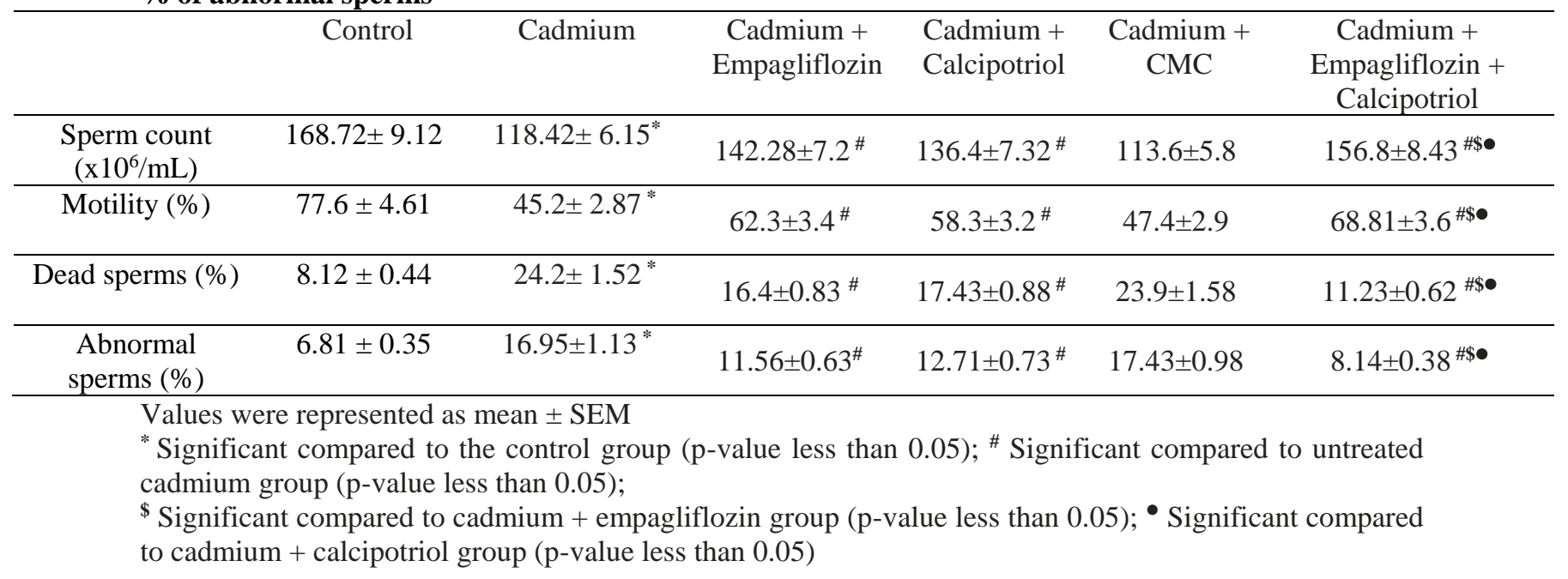

Table 5: Correlation between tissue TBARS and the sperm characteristics

\begin{tabular}{ccc}
\hline Tissue TBARS & Pearson's (r) & P-value \\
\hline Sperm count & -0.624 & 0.025 \\
\hline Motility & -0.436 & 0.036 \\
\hline Dead sperms & 0.547 & 0.032 \\
\hline Abnormal sperms & 0.611 & 0.022 \\
\hline
\end{tabular}

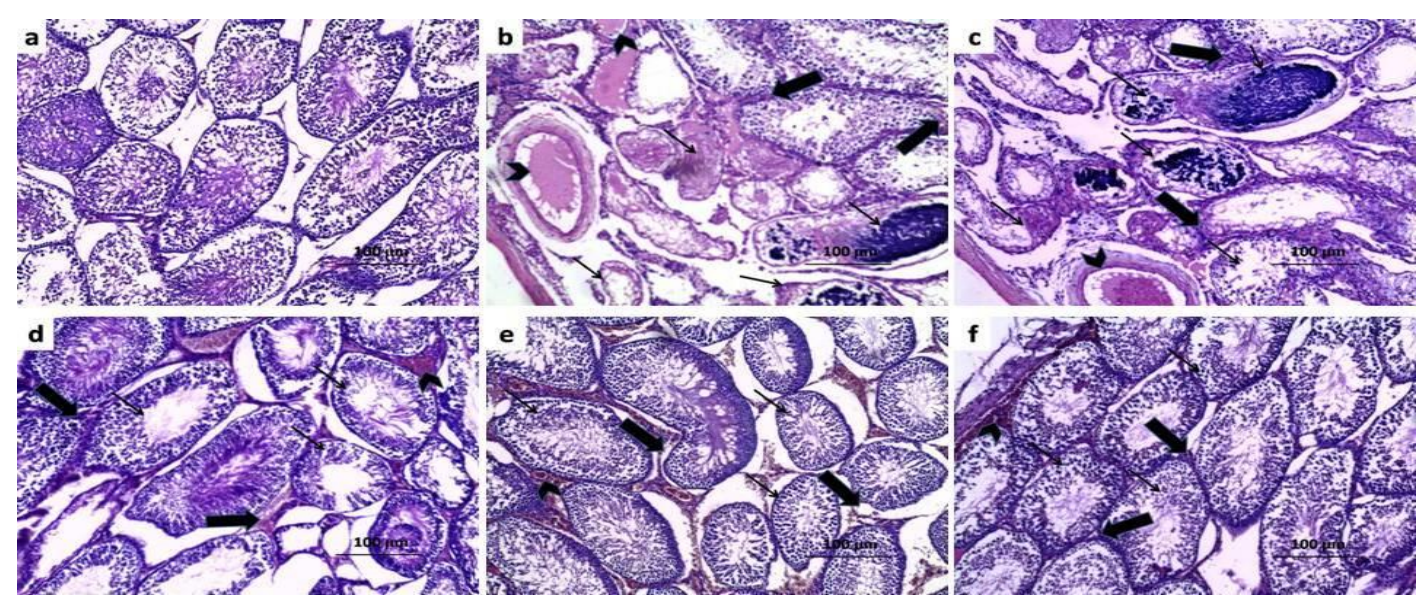

Figure 1: Sections of the testis (H\&E x200) from a) Control group with normal morphology of the seminiferous tubules, interstitial tissue, spermatogenic cells and spermatozoa; b) Cadmium group showing degenerated interstitial tissue (Thick arrow) with marked congestion (Arrow head) and disorganization of the epithelium of the seminiferous tubules with decrease in the germinal cells and immature germinal epithelial cells in the lumen (Thin arrow); c) Cadmium + CMC group showing significant degeneration of the seminiferous tubules (Thin arrow) with degeneration of the interstitial tissue (Thick arrow) with marked congestion (Arrow head); d) Cadmium + Empagliflozin group showing significant decrease in the degeneration of the interstitial tissue (Thick arrow) with most of the seminiferous tubules showing organized epithelium (Thin arrow) with mild congestion (Arrow head); e) Cadmium + Calcipotriol group showing significant improvement in the morphology of the seminiferous tubules (Thin arrow) with apparently normal interstitial tissue (Thick arrow); f) Cadmium + Empagliflozin + Calcipotriol group showing apparently normal seminiferous tubules (Thin arrow) and interstitial tissue (Thick arrow) with minimal congestion (Arrow head). 


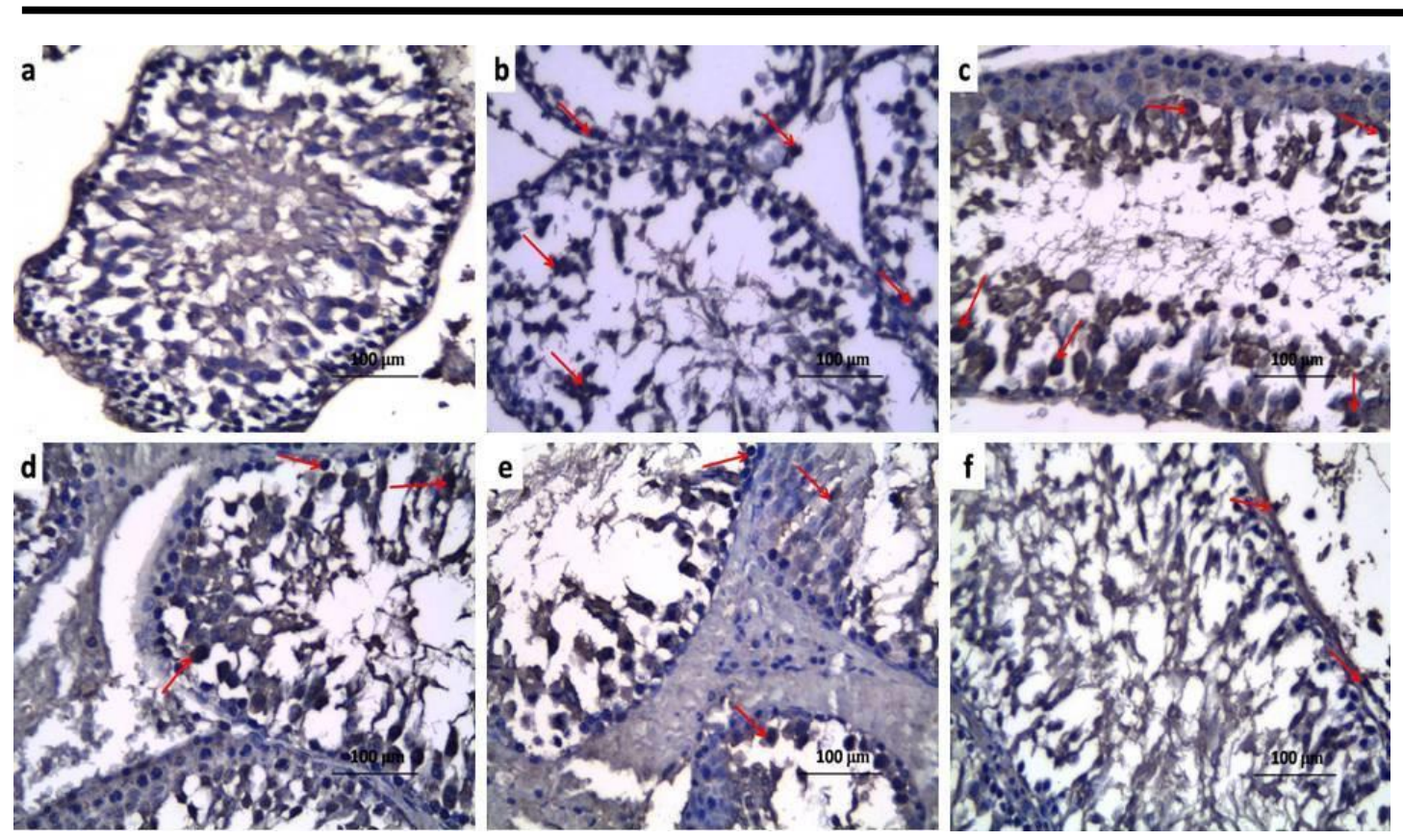

Figure 2: Testicular sections of immunohistochemical staining of NF- $\kappa B(p 65)(x 400)$ of a) Control group revealing negative immunostaining for $\mathrm{NF}-\kappa \mathrm{B}(\mathrm{p} 65)$; b) Cadmium group revealing strong positive immunostaining for NF- $\mathrm{KB}$ (p65) (Arrow); c) Cadmium + CMC group revealing strong positive immunostaining for $\mathrm{NF}-\kappa \mathrm{B}$ (p65) (Arrow);d) Cadmium + Empagliflozin group revealing moderate positive immunostaining for NF- $\mathrm{B}$ (p65) (Arrow);e) Cadmium + Calcipotriol group revealing moderate positive immunostaining for NF- $\mathrm{NB}$ (p65) (Arrow); f) Cadmium + Empagliflozin + Calcipotriol group revealing weak positive immunostaining for $\mathrm{NF}-\kappa \mathrm{B}$ (p65) (Arrow).

\section{Discussion}

In the present study, cadmium induced significant deterioration of the testicular functions compared to the control group. This was in agreement with Babaknejad et al. [23] and $\mathrm{Wu}$ et al. [24] who found that cadmium induces significant atrophy in the seminiferous tubules and markedly affects energy production in the spermatogenic cells. Zhang et al. [25] reported that cadmium interferes with the division of spermatogenic cells and induces denaturation of the epithelium of the seminiferous tubules and phagocytosis of Sertoli cells together with significant regression in testicular development and weight. These changes were ameliorated in our study with administration of empagliflozin and/or calcipotriol. Liu et al. [26] reported that supplementation with viamin $D$ and its derivatives may significantly improve the testicular functions. Also, Purcell and Moley [27] suggested that targeting sodium glucose cotransporter- 2 in the testis may have a positive impact on the testicular functions.

In the present study, cadmium administration induced significant decrease in serum testosterone, FSH and $\mathrm{LH}$ compared to the control group. This was in agreement with Siu et al. [4] who reported that cadmium induced significant decrease in serum testosterone, $\mathrm{LH}$ and FSH which in 
turn will affect the process of spermatogenesis as well as on the morphology of the seminiferous tubules. This decrease was ameliorated in the present study with administration of calcipotriol which was in accordance with Nimptsch et al. [28] who stated that vitamin D and its derivatives have the ability to improve the serum levels of sex hormones due to their potent antioxidant effects. Also, empagliflozin in our study induced significant increase in serum testosterone, FSH and LH compared to the group treated with cadmium alone. This may be attributed to the antioxidant and anti-inflammatory properties of empagliflozin which may ameliorate the toxic effects of cadmium on the synthesis of androgens [29].

In the present study, cadmium administration induced significant decrease in the sperm motility and count together with significant increase in the percentage of dead and abnormal forms of sperms compared to the control group. This was in agreement with Mahmoudi et al. [30] who reported that cadmium administration disrupts the maturation of the spermatogenic cells and alters spermatogonia DNA and sperm morphology. Also, it was suggested that cadmium decreases the number of Sertoli cells and causes widespread death of the germ cells which is usually followed by significant deterioration in testicular morphology and the sperm characteristics
[31]. This was attenuated in the present study with administration of calcipotriol which was in the same line with BaSalamah et al. [32] who reported that vitamin D and its derivatives can restore the normal functions of the spermatogenic cells and antagonize the deleterious effects of cadmium and lead on Sertoli cells and germ cells. Also, empagliflozin in our study had the ability to improve the sperm characteristics compared to cadmium-treated group. This may be due to the ability of empagliflozin to improve energy production by the mitochondria and inhibit DNA damage induced by cadmium administration to rats [33].

Oxidative stress is thought to be the main mechanism incriminated in the testicular damage induced by cadmium [2]. Patra et al. [34] reported that cadmium induces significant DNA damage with subsequent production of reactive oxygen species (ROS) which in turn suppress the activities of the antioxidant enzymes leading to significant deterioration of the sperm characteristics and testicular functions. These effects were attenuated in the present study with administration of calcipotriol which was in the same line with Saedisomeolia et al. [35] who stated that calcipotriol may exert significant antioxidant effects by enhancing the activity of the antioxidant enzymes and decreasing ROS production. Also, empagliflozin in our study 
had the ability to increase the activity of the antioxidant enzymes and decrease TBARS production which was in agreement with Zhou et al. [9] who attributed the antioxidant effects of empagliflozin to activation of AMP-activated protein kinase which subsequently increases the activity of the antioxidant enzymes leading to significant amelioration of oxidative stress.

In the present study, tissue TBARS levels showed significant positive correlation with the percentage of dead sperms and abnormal sperm forms and showed significant negative correlation with the sperm count and motility. This was in the same line with Alkan et al. [36] and Cruz et al. [37] who reported that the increase verified in oxidative stress parameters such as tissue TBARS concentration is correlated with the disturbed sperm characteristics observed in semen analyses because lipid peroxidation interferes with the integrity of the spermatozoa membrane which in turn will be reflected on various sperm characteristics.

Coinciding with the results of the present study, $\mathrm{Du}$ et al. [38] found that cadmium increased mRNA expression of TGF- $\beta 1$, TNF- $\alpha$ and IL-6 which in turn induces severe inflammatory reactions leading to significant damage of the testicular tissues. Moreover, Freudlsperger et al. [39] reported that there is a strong relationship between TGF- $\beta 1$ and $\mathrm{NF}-\kappa \mathrm{B}$ signaling pathways which may significantly modulate the inflammatory cascade. They found that the significant increase in TGF$\beta 1$ levels induces NF- $\kappa B$ gene activity which was in the same line with the results of the present study where cadmium administration induced significant increase in TGF- $\beta 1$, IL-6 and NF- $\kappa \mathrm{B}$ levels compared to the control group.

The present study proved the antiinflammatory properties of empagliflozin and/or calcipotriol where administration of each of these agents resulted in significant decrease in TGF- $\beta 1$, IL- 6 and NF- $\kappa$ B levels compared to rats treated with cadmium alone. Segaert et al. [40] attributed the antiinflammatory properties of calcipotriol to its inhibitory actions on the effects of Th1 and Th17 cytokines, which subsequently inhibits the secretion of TNF- $\alpha$ and IL-17. Moreover, calcipotriol was proven to attenuate $\quad$ TGF- $\beta 1 / \mathrm{NF}-\kappa \mathrm{B} \quad$ signaling pathways [41]. Also, Jojima et al. [42] reported that empagliflozin can inhibit the expression of the proinflammatory cytokines, possibly through affection of mRNA expression of NF- $\kappa \mathrm{B}$ and TGF- $\beta 1$.

In the present study, empagliflozin/calcipotriol combination induced significant improvement of the testicular functions, sperm characteristics, hormonal profile and the antioxidant defenses associated with amelioration of the inflammatory processes and improvement of 
the histopathological and immunohistochemical picture compared to the use of each of these drugs alone. This may be due to the combined antioxidant and anti-inflammatory properties of both drugs together with their ability to affect TGF$\beta 1 / N F-\kappa B$ signaling which may have a positive impact on the testicular functions and the sperm characteristics. This may be due to the hypothesis that sodium glucose cotransporter-2 (SGLT2) may regulate the absorption and metabolism of vitamin D and its derivatives such as calcipotriol which in turn may affect the testicular functions [43].

\section{Conclusion}

Empagliflozin/calcipotriol

combination might represent a promising therapeutic modality for amelioration of cadmium-induced testicular toxicity, possibly due to their antioxidant and antiinflammatory properties together with their ability to improve the hormonal profile, sperm characteristics and testicular functions.

\section{Conflict of interest}

The authors had no conflict of interest to declare.

\section{References}

[1] Zhai Q, Narbad A, Chen W. Dietary strategies for the treatment of cadmium and lead toxicity. Nutrients 2014; 7(1): $552-571$.

\section{[2] Rafati Rahimzadeh M, Rafati Rahimzadeh M, Kazemi S,}

Moghadamnia AA. Cadmium toxicity and treatment: An update. Caspian $\mathrm{J}$ Intern Med 2017; 8(3):135-145.

[3] Prozialeck WC, Edwards JR, Woods JM. The vascular endothelium as a target of cadmium toxicity. Life Sci 2006; 79: 1493-1506.

[4] Siu ER, Mruk DD, Porto CS, Cheng CY. Cadmium-induced testicular injury. Toxicol Appl Pharmacol 2009; 238(3): 240-249.

[5] Kalra S, Singh V, Nagrale D. SodiumGlucose Cotransporter-2 Inhibition and the Glomerulus: A Review. Adv Ther 2016; 33(9):1502-1518.

[6] Kohler S, Zeller C, Iliev H, Kaspers S. Safety and Tolerability of Empagliflozin in Patients with Type 2 Diabetes: Pooled Analysis of Phase IIII Clinical Trials. Adv Ther 2017; 34(7): 1707-1726.

[7] Hattori S. Anti-inflammatory effects of empagliflozin in patients with type 2 diabetes and insulin resistance. Diabetol Metab Syndr 2018; 10: 93.

[8] Lee KA, Jin HY, Lee NY, Kim YJ, Park TS. Effect of Empagliflozin, a Selective Sodium-Glucose Cotransporter 2 Inhibitor, on Kidney and Peripheral Nerves in Streptozotocin-Induced Diabetic Rats. Diabetes Metab J 2018; 42(4): 338-342. 
[9] Zhou H, Wang S, Zhu P, Hu S, Chen Y, Ren J. Empagliflozin rescues diabetic myocardial microvascular injury via AMPK-mediated inhibition of mitochondrial fission. Redox Biol 2018; 15: 335-346.

[10] Emanuelsson I, Wikvall K, Friman T, Norlin M. Vitamin D Analogues Tacalcitol and Calcipotriol Inhibit Proliferation and Migration of T98G Human Glioblastoma Cells. Basic Clin Pharmacol Toxicol 2018; 123(2): 130136.

[11] Lin Z, Li W. The Roles of Vitamin D and Its Analogs in Inflammatory Diseases. Curr Top Med Chem 2016; 16(11): 1242-1261.

[12] Ito I, Waku T, Aoki M, Abe R, Nagai Y, Watanabe T, Nakajima Y, Ohkido I, Yokoyama K, Miyachi H, Shimizu T, Murayama A, Kishimoto H, Nagasawa K, Yanagisawa J. A nonclassical vitamin $\mathrm{D}$ receptor pathway suppresses renal fibrosis. J Clin Invest 2013; 123(11): 4579-4594.

[13] Ige SF, Olaleye SB, Akhigbe RE, Akanbi TA, Oyekunle OA, Udoh UA. Testicular toxicity and sperm quality following cadmium exposure in rats: Ameliorative potentials of Allium cepa. J Hum Reprod Sci 2012; 5(1): $37-42$.

[14] Li C, Zhang J, Xue M, Li X, Han F, Liu X, Xu L, Lu Y, Cheng Y, Li
T, Yu X, Sun B, Chen L. SGLT2 inhibition with empagliflozin attenuates myocardial oxidative stress and fibrosis in diabetic mice heart. Cardiovasc Diabetol 2019; 18(1):15.

[15] Ding N, Yu RT, Subramaniam N, et al. A vitamin $\mathrm{D}$ receptor/SMAD genomic circuit gates hepatic fibrotic response. Cell 2013; 153(3): 601-613.

[16] Sinha AK. Colorimetric assay of catalase. Anal Biochem 1972; 47: 389394.

[17] Lowry OH, Rosebrough NJ, Farr AL, Randall RJ. Protein measurement with the Folin phenol reagent. J Biol Chem 1951; 193: 265-275.

[18] Khaki A, Khaki AA, Hajhosseini L, Golzar FS, Ainehchi N. The AntiOxidant Effects of Ginger and Cinnamon on Spermatogenesis Dysfunction of Diabetes Rats. Afr J Tradit Complement Altern Med 2014; 11: $1-8$.

[19] Badkoobeh P, Parivar K, Kalantar SM, Hosseini SD, Salabat A. Effect of nano-zinc oxide on doxorubicininduced oxidative stress and sperm disorders in adult male Wistar rats. Iran J Reprod Med 2013; 11: 355-364.

[20] Zahra A, Gholamreza N, Farokhi F, Shalizar Jalali A. Attenuation of Cyclosporine-Induced Sperm Impairment and Embryotoxicity by 
Crataegus monogyna Fruit Aqueous

Extract. Cell J 2013; 15: 198-205.

[21] Shalizar Jalali A, Hasanzadeh S, Malekinejad H. Chemoprotective effect of Crataegus monogyna aqueous extract against cyclophosphamideinduced reproductive toxicity. Vet Res Forum 2011; 2: 266-273.

[22] Kabel AM, Omar MS, Alhadhrami A, Alharthi SS, Alrobaian MM. Linagliptin potentiates the effect of 1dopa on the behavioural, biochemical and immunohistochemical changes in experimentally-induced Parkinsonism: Role of toll-like receptor 4 , TGF- $\beta 1$, $\mathrm{NF}-\kappa \mathrm{B}$ and glucagon-like peptide 1 . Physiol Behav 2018; 188:108-118. Babaknejad N, Bahrami

S, Moshtaghie AA, Nayeri H, Rajabi

P, Iranpour FG. Cadmium Testicular Toxicity in Male Wistar Rats: Protective Roles of Zinc and Magnesium. Biol Trace Elem Res 2018; 185(1): 106-115.

[24] Wu X, Guo X, Wang H, et al. A brief exposure to cadmium impairs Leydig cell regeneration in the adult rat testis. Sci Rep 2017; 7(1): 6337.

[25] Zhang $M$, He $Z$, Wen $L$, et al. Cadmium suppresses the proliferation of piglet Sertoli cells and causes their DNA damage, cell apoptosis and aberrant ultrastructure. Reprod Biol Endocrinol 2010; 8:97.
[26] Liu Y, He Y, Wang Q, et al. Vitamin D3 supplementation improves testicular function in diabetic rats through peroxisome proliferator-activated receptor- $\gamma /$ transforming growth factorbeta 1/nuclear factor-kappa B. J Diabetes Investig 2019; 10(2): 261271.

[27] Purcell SH, Moley KH. Glucose transporters in gametes and preimplantation embryos. Trends Endocrinol Metab 2009; 20(10): 483489.

[28] Nimptsch K, Platz EA, Willett WC, Giovannucci E. Association between plasma 25-OH vitamin $\mathrm{D}$ and testosterone levels in men. Clin Endocrinol (Oxf) 2012; 77(1): 106112.

[29] Ding GL, Liu Y, Liu ME, Pan JX, Guo MX, Sheng JZ, Huang HF. The effects of diabetes on male fertility and epigenetic regulation during spermatogenesis. Asian J Androl 2015; 17: 948-953.

[30] Mahmoudi R, Azizi A, Abedini S, Hemayatkhah Jahromi V, Abidi H, Jafari Barmak M. Green tea improves rat sperm quality and reduced cadmium chloride damage effect in spermatogenesis cycle. J Med Life 2018; 11(4): 371-380.

[31] Yang SH, Yu LH, Li L, et al. Protective Mechanism of Sulforaphane 
on Cadmium-Induced Sertoli Cell

Injury in Mice Testis via Nrf2/ARE

Signaling Pathway. Molecules 2018;

23(7): 1774.

[32] BaSalamah MA, Abdelghany AH, ElBoshy M, Ahmad J, Idris S, Refaat B. Vitamin D alleviates lead induced renal and testicular injuries by immunomodulatory and antioxidant mechanisms in rats. Sci Rep 2018; 8(1): 4853.

[33] Elmaaboud MA , Kabel AM , Elrashidy M. Pre-treatment with Empagliflozin ameliorates Cisplatin induced acute kidney injury by suppressing apoptosis. J Appl Biomed 17(1): 82-90.

[34] Patra RC, Rautray AK, Swarup D.

Oxidative stress in lead and cadmium toxicity and its amelioration. Vet Med Int 2011; 2011: 457327.

[35] Saedisomeolia A, Taheri E, Djalali M, Djazayeri A, Qorbani M, Rajab A, Larijani B. Vitamin D status and its association with antioxidant profiles in diabetic patients: A cross-sectional study in Iran. Indian J Med Sci 2013; 67(1-2): 29-37.

[36] Alkan İ, Yüksel M, Canat HL, Atalay HA, Can O, Özveri H, et al. Superoxide Anion Production by the Spermatozoa of Men with Varicocele: Relationship with Varicocele Grade and
Semen Parameters. World J Mens Health 2018; 36(3):255-262.

[37] Cruz DF, Lume C, Silva JV, Nunes A, Castro I, Silva R, et al. Oxidative stress markers: Can they be used to evaluate human sperm quality? Turk J Urol 2015; 41(4):198-207.

[38] Du L, Lei Y, Chen J, Song H, Wu X. Potential Ameliorative Effects of Qing Ye Dan Against Cadmium Induced Prostatic Deficits via Regulating Nrf2/HO-1 and TGF- $\beta 1 /$ Smad Pathways. Cell Physiol Biochem 2017;43(4): 1359-1368.

[39] Freudlsperger C, Bian Y, Contag Wise S, Burnett J, Coupar J, Yang X, Chen Z, Van Waes C. TGF- $\beta$ and $\mathrm{NF}-\kappa \mathrm{B}$ signal pathway cross-talk is mediated through TAK1 and SMAD7 in a subset of head and neck cancers. Oncogene 2013; 32: 1549-1559.

[40] Segaert S, Shear NH, Chiricozzi A, et al. Optimizing Anti-Inflammatory and Immunomodulatory Effects of Corticosteroid and Vitamin D Analogue Fixed-Dose Combination Therapy. Dermatol Ther (Heidelb) 2017; 7(3): 265-279.

[41] Zhao H, Li S, Luo F, Tan Q, Li H, Zhou W. Portulaca oleracea L. aids calcipotriol in reversing keratinocyte differentiation and skin barrier dysfunction in psoriasis through inhibition of the nuclear factor $\kappa \mathrm{B}$ 
signaling pathway. Exp Ther Med 2015;9(2): 303-310.

[42] Jojima $T$, Tomotsune $T$, Iijima $T$, Akimoto K, Suzuki K, Aso Y. Empagliflozin (an SGLT2 inhibitor), alone or in combination with linagliptin (a DPP-4 inhibitor), prevents steatohepatitis in a novel mouse model of non-alcoholic steatohepatitis and diabetes. Diabetol Metab Syndr 2016; 8: 45 .

[43] Ye Y, Zhao C, Liang J, Yang Y, Yu M, Qu X. Effect of Sodium-Glucose Co-transporter 2 Inhibitors on Bone Metabolism and Fracture Risk. Front Pharmacol 2019; 9:1517. 